\title{
Speed governor design based on fuzzy self-tuning PID method for marine diesel engine
}

\author{
Qiaomei Sun ${ }^{1, a^{*}}$, Jinguo Chen ${ }^{2, b}$ \\ ${ }^{1}$ College of Mechanical \& Power Engineering, China Three Gorges University, Yichang,China \\ ${ }^{2} 710$ th Research Institute of China Shipbuilding Industry Corporation, Yichang, China \\ asunqm@ctgu.edu.cn, b150321544@qq.com
}

\begin{abstract}
Keywords: Speed regulation system; Fuzzy control; Diesel engine; Simulink
Abstract. As the most commonly used method in speed governor for marine diesel engine, PID control method is not very effective for nonlinear systems with big variation of parameters. To improve the dynamic precision of diesel speed governor, a fuzzy PID hybrid controller of parameter self-adjusting is put forward in this paper. The mathematical model of diesel engine and its speed regulation system are presented and computer simulation is conducted in Matlab software. Simulation results verify that the proposed method improves the control accuracy of speed of diesel engine compared with conventional PID controller.
\end{abstract}

\section{Introduction}

Ship speed control is a key issue in improving performance of ship maneuvers and keeping ship speed stabilization. The navigation speed of ship depends on crankshaft speed of diesel engine. Speed regulator of marine diesel engine as the control object can realize good performance[1].

In diesel speed control systems, PID controller is the most commonly used because of its simple structure, easy accomplishment and perfect performance in condition of small parameter variation. However, speed governing system of marine diesel engine is a complicated non-linear and time variable system. And PID control method is not very effective for nonlinear systems with big variation of parameters[2].For the contradictions between static and dynamic performance, track the setting value and the disturbance rejection, robustness and control performance, PID controller has not been a very good solution, so it often had to compromise to get the best control effect. To overcome these shortcomings, it is necessary to bring intelligence technology to diesel as higher requirement for speed regulation.

Recent years, many scholars and researchers studies on several kinds of advanced control theories and algorithms in diesel speed regulation. Huang [3] designed a controller for a diesel engine speed regulation system using $\mathrm{H} 2$ control theory, which rests on the problem of mixed sensitivity. Shi et al proposed and implemented a controller combined with cerebellar model articulation controller (CMAC) neural network to the speed control of marine diesel generating set [4]. Comparison on power generation frequency with that of the production controller shows that the CMAC-PID controller has the similar performance. Wang et al. established a modified volumetric model of a large-scale low-speed electronically controlled marine diesel engine, which can predict the pressure history and thermodynamic parameters [5]. Yuan et al. set up full range electric governor model based on the experiment of electric controlled LPG diesel dual fuel engine and realized closed loop of engine speed in suddenly changing of load by adjusting dynamic fuel pump rack position [6]. Some references investigate the performance of robust controllers and fuzzy controllers for diesel engine control [7].

In recent years fuzzy models of nonlinear systems have attracted huge interest from scholars and scientists. Fuzzy logic control, as relatively more understandable whereas expert knowledge can be incorporated conveniently, is usually preferred by control engineers [8-10].

To overcome shortcomings of conventional controller, a strategy based on fuzzy self-tuning PID controller is studied in this paper. Firstly an engine model will be presented for a 2-stroke cylinder diesel engine is presented based on Mean Value Engine Model (MVEM) .Then speed governors designed using two control methods: conventional PID and fuzzy self-tuning PID method will be 
discussed. Both controllers will be implemented on Matlab software. Computer simulations will be conducted and results will be analyzed in the last section.

\section{Mathematical model of diesel engine}

Mean Value Engine Model (MVEM) has been widely used in model based engine control development. In this paper, MVEM is adopted for a 2-stroke cylinder diesel engine model. Owing to space limitations, the MVEM model is not discussed in detail, which can be found in references $[3,4,6,8]$.

A turbocharged diesel engine can be thought of as made up by five components of system, gas path of which links to each other, drive shaft of some components are connected in mechanical way. In this paper, these components are considered: diesel engine cylinder, turbocharger, air intercooler, an intake manifold and an exhaust pipe.

The objective of the diesel engine model is to develop speed control of the engine. Here the cycle fuel feeding and the engine rotational speed $n$ are considered to be main model input and the main output of the mean value engine model respectively.

\section{PID speed regulator design}

PID controller has simple structure, stable performance and strong robustness, can get good effect for clear mathematical model of controlled object, and is the most common method in electronic diesel speed control systems.

Since computer control is a sampling method, the control variable is calculated by deviation value at sampling instant. Diesel engine fuel increment controlled by PID controller can be described by the following equation:

$$
\begin{aligned}
& \Delta y=k_{f}\left(n_{r e f_{n}}-n_{r e f_{n-1}}\right)+k_{p}\left(e_{n}-e_{n-1}\right)+\frac{\Delta T}{T_{i}} e_{n}+\frac{T_{d}}{\Delta T}\left[\left(e_{n}-e_{n-1}\right)-\left(e_{n-1}-e_{n-2}\right)\right] \\
& y_{n}=y_{n-1}+\Delta y
\end{aligned}
$$

Where $k_{f}$ is feedforward gain coefficient, usually less than $1 ; n_{r e f n}$ is setting value of rotational speed at time step $n ; n_{\text {refn-l }}$ is setting value of rotational speed at time step $n-1 ; \Delta T$ is sampling time ; $T_{i}$ is integral time constant; $T_{d}$ is derivative time constant; $k_{p}$ is proportional gain coefficient; $e_{n}$ is deviation value at time step $n ; e_{n-1}$ is deviation value at time step $n-1 ; e_{n-2}$ is deviation value at time step $n-2$.

The oil supply executive function of electronic governor is to turn throttle position signal into actual position of the fuel pump rack, which is simplified as proportional and inertia elements in the simulation of diesel engine.

The relationship of cycle fuel feeding of fuel supply device $g_{f}$, diesel engine rotation speed $\mathrm{n}$ and the fuel pump rack position $y$ can be obtained by the experimental data regression analysis computation formula in the following equation:

$$
g_{f}=0.006749(y-32.09) * n+18.84
$$

\section{Design of Fuzzy PID controller}

Diesel engine has non-stationary and nonlinear complex features. The optimal PID controller parameters are constantly changing, which leads to conditions that parameters are not the best parameters of PID controller. Fuzzy control is a kind of intelligent control method, in which control experience is expressed in the form of control rules, with many characteristics of smooth control process and good adaptability, but it essentially cannot eliminate static error. 
Combining the two, according to the design experience of PID controller, fuzzy control method is adopted as adjust strategy of PID control parameters and realize online real-time parameter adjustment of PID controller. This fuzzy-PID controller is actually a nonlinearization of PID controller, establishing a map relationship between system characteristic change and control variables. Integrating PID and fuzzy control of simplicity, flexibility and robustness, will be a kind of intelligent controller with better performance.

The controller has two inputs and three outputs according to the control purpose and requirements. The inputs are deviation $E$ between the setting value and actual value of speed and its changing rate $E C$ multiplied by the corresponding quantitative factor and the outputs are $K P, K I$, and $K D$, and then multiplied by quantitative factor $C P, C I$ and $C D$, then proportional, integral and differential constants $K p K i$ and $K d$ are obtained.

The speed regulation system based on fuzzy self-tuning PID method is shown in Fig.1.

Here, Fuzzy set of $E$ is set to be

$$
\{N B, N M, N S, N S S, Z O, P S S, P S, P M, P B\} .
$$

Fuzzy set of $E C$ is set to be

$$
\{N B, N M, N S, Z O, P S, P M, P B\} \text {. }
$$

Fuzzy sets of $K P, K I$ and $K D$ all are set to be

$$
\{Z O, S, M S, M, M B, B\} \text {. }
$$

Where, $N$ denotes Negative, $P$ denotes positive, $B$ denotes Big, $M$ denotes Medium, $S$ denotes Small, $Z O$ denotes $Z E R O$. In order to make control tuning easier, only triangular functions have been chosen.

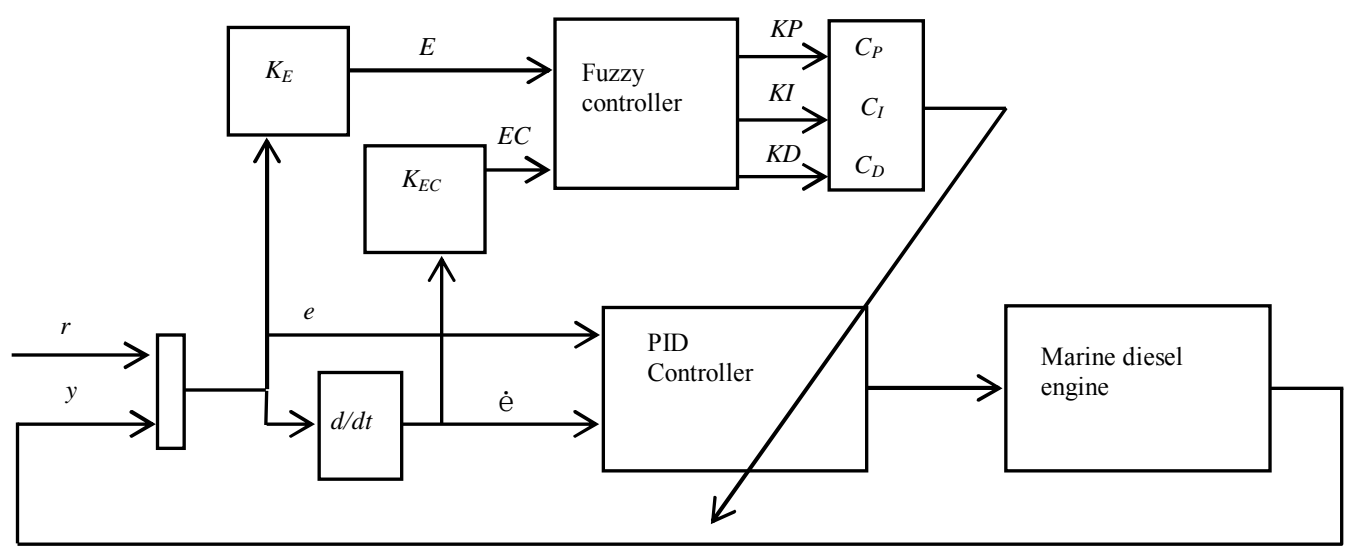

Fig.1.Control system design based on fuzzy self-tuning PID method

The domain of discourse of $E$ and $E C$ is $\{-10,10\}$, and domain of discourse of $K P, K I$ and $K D$ is $\{0,1\}$. We set $K E$ and $K E C$ respectively to 0.01 and 0.04 . This is equivalent to the domain of discourse of e and è respectively [- 1000 1000] and [- 250250$]$. Quantitative factors $C P, C I$ and $C D$ of outputs are very important to affect the control effect. Firstly they can be set to 1 , and then finetuning is applied in actual simulation to get good performance.

Fuzzy controller using Mamdani inference, the control rules are obtained by controller's experience. Based on the definition of input and output variables, fuzzy control rules are obtained here 63 total rules, which in the form of the following:

If $\{E$ is $A$ and $E C$ is $B\}$ Then $\{K P$ is $C, K l$ is $D, K D$ is $E\}$

The maximum membership degree method, the weighted average method and gravity method can be considered as disfuzzification methods. Here gravity method is chosen in this paper. 


\section{Simulation results}

The diesel engine speed regulation system researched in this paper is required to track the speed setting value as the reference input signal.Taking $6 \mathrm{~S} 35 \mathrm{MC}$ diesel engine made by MAN-B\&W as a prototype, simulation and calculation are conducted. This engine has 6 cylinders with diameter of $350 \mathrm{~mm}$ and two strokes. Its main parameters are shown in Table 1. Injection volume of oil into cylinderand external load torque aretheinputs of the model. The main output of the diesel engine modelis crankshaft speed. The amount of fuel injection into the cylinder is adjusted by external governor.

Table 1 Parameters of 6S35MC diesel engine

\begin{tabular}{|c|c|c|c|}
\hline Diesel engine type & $6 \mathrm{~S} 35 \mathrm{MC}$ & Firing order & $1-5-3-6-2-4$ \\
\hline number of cylinders & 6 & Diameter of cylinder [mm] & 350 \\
\hline Stroke[mm] & 1400 & Number of strokes & 2 \\
\hline Geometry compression ratio & 18.8 & rated power[kW] & 4400 \\
\hline $\begin{array}{l}\text { crank radius-connecting rod } \\
\text { length ratio }\end{array}$ & 0.436 & $\begin{array}{c}\text { maximum continuous rating } \\
{[\mathrm{kW}]}\end{array}$ & 4440 \\
\hline mean effective pressure $[\mathrm{MPa}]$ & 1.93 & Rated speed[r/min $]$ & 173 \\
\hline maximum cylinder pressure $[\mathrm{MPa}]$ & 14.6 & Type of turbocharger & NA40/S \\
\hline $\begin{array}{l}\text { fuel consumption }[\mathrm{g} / \mathrm{kWh}](100 \% \\
\text { load) }\end{array}$ & 178 & $\begin{array}{c}\text { System lubricating oil } \\
\text { consumption rate }[\mathrm{kg} / \mathrm{cyl} 24 \mathrm{~h}]\end{array}$ & 2.0 \\
\hline $\begin{array}{l}\text { Cylinder oil consumption } \\
\text { rate }[\mathrm{g} / \mathrm{KWh}]\end{array}$ & $1.1-1.6$ & Piston average speed $[\mathrm{m} / \mathrm{s}]$ & 8.07 \\
\hline
\end{tabular}

At the start of the simulation the diesel engine running at rated conditions, namely load is $100 \%$, and the speed is set to $173 \mathrm{r} / \mathrm{min}$. After 60 seconds, setting speed suddenly changes from the rated speed to $138 \mathrm{r} / \mathrm{min}$, and after 200 seconds changes to $158 \mathrm{r} / \mathrm{min}$, in which the changes of the various performance parameters of diesel engine can be observed and dynamic performance of model working can be obtained. Two control methods are considered for the governor in this paper: conventional PID and fuzzy self-tuning PID method. Both are implemented on Matlab software. Simulation results are shown in Fig.2.
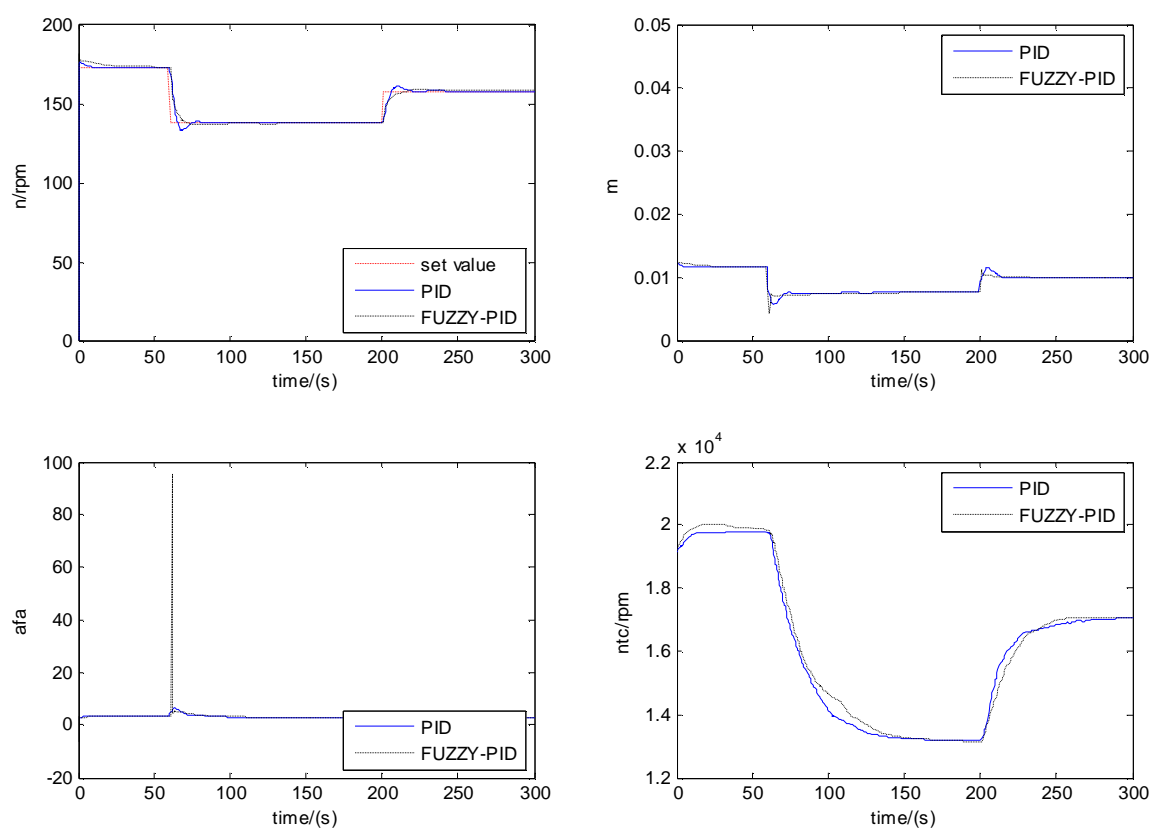

Fig.2. simulation results of set speed suddenly changing

After suddenly decreasing of the speed setting value, due to the actionof conventional PIDand fuzzy-PID speed governor, the actual crankshaft speed of diesel tracks the reference setting valuefast. In PID method, the dynamic variation ratio of speedis $2.2 \%$ and thestabilization time is $8 \mathrm{~s}$, which are 
reduced to $1.1 \%$ and $5 \mathrm{~s}$ respectively in fuzzy self-tuning PID method.After suddenly increasing of speed setting value, the speed of diesel tracks the reference setting value fast.In PID method the dynamic variation ratio of speed is $1.9 \%$ and the stabilization time is $6 \mathrm{~s}$, which are reduced to $0.6 \%$ and $3 \mathrm{~s}$ respectively in fuzzy self-tuning PID method. Differences between dynamic variation ratio and stabilization time are shown in Table 2.

Table 2 Simulation results of rotational speed of diesel

\begin{tabular}{|c|c|c|c|c|c|c|}
\hline & \multicolumn{3}{|c|}{ speed decrease } & \multicolumn{3}{c|}{ speed increase } \\
\hline overshoot & $\begin{array}{c}\text { dynamic } \\
\text { variation ratio } \\
\%\end{array}$ & $\begin{array}{c}\text { Stabilization } \\
\text { time }\end{array}$ & overshoot & $\begin{array}{c}\text { dynamic } \\
\text { variation ratio } \\
\%\end{array}$ & $\begin{array}{c}\text { stabilization } \\
\text { time }\end{array}$ \\
\hline PID & 4 & 2.2 & 8 & 3 & 1.9 & 6 \\
\hline $\begin{array}{c}\text { Fuzzy } \\
\text { PID }\end{array}$ & 2 & 1.1 & 5 & 1 & 0.6 & 3 \\
\hline
\end{tabular}

From computer simulation results, it can be seen that overshoot has decreased significantly, the dynamic variation ratio of speed has declined evidently and the stabilization time is shortened to a great extent.The proposed governor has improved theperformance of dynamic precision of speed regulation system. The robustness of the fuzzy self-tuning controller has been tested.
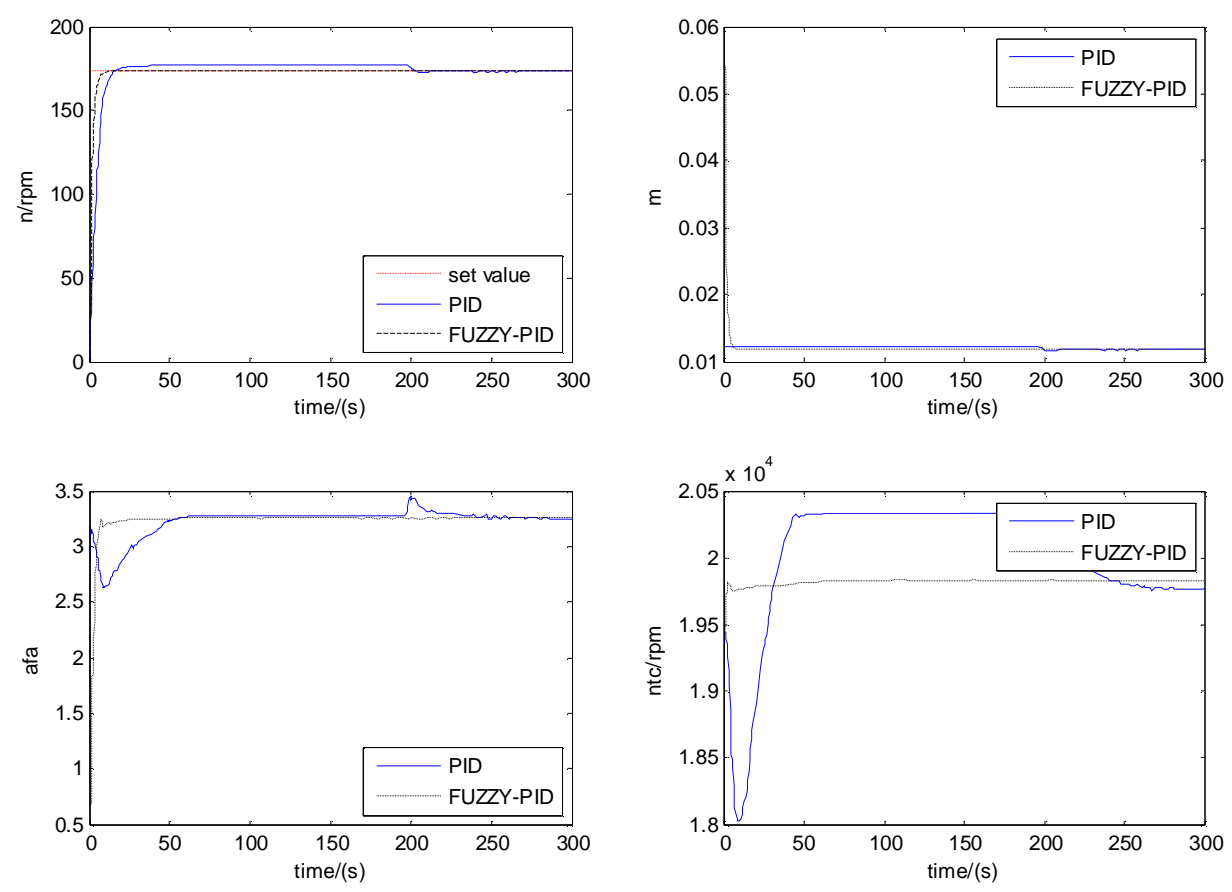

Fig.3. simulation results of starting condition

In mode of start, rotational speed of diesel engine changes from 0 to $173 \mathrm{r} / \mathrm{min}$. simulation results are shown in Fig.3. The $n$ plot shows that the $n$ value increases in a shorter time with less overshoot than PID controller. Cycle fuel feeding, excess air coefficient and turbine speed are also shown in the graphs. As illustrated by Fig.3, the errors of FUZZY-PID ingraphs have been considerably reduced andhigher accuracy is than conventional PID strategy. Starting time, rotational speed overshoot,and dynamic variation ratio of mode of start are shown in Table 3. It reveals that the robust stability is better than PID controllers. 
Table 3 Simulation results of rotational speed of diesel starting

\begin{tabular}{|c|c|c|c|c|}
\hline & Start speed & overshoot & $\begin{array}{c}\text { dynamic variation ratio } \\
\%\end{array}$ & Start time \\
\hline PID & 173 & 31 & 17.9 & 18 \\
\hline Fuzzy PID & 173 & 3 & 1.7 & 7 \\
\hline
\end{tabular}

\section{Conclusion}

This paper has derived a fuzzy self-tuning PID speed regulation system of a turbocharged diesel engine.Based on the structure and running mechanism of marine diesel engine $6 \mathrm{~S} 35 \mathrm{MC}$, nonlinear mathematic model of ship diesel engine is established.As for defects and deficienciesof the traditional PID control algorithm for adjustment of nonlinear model, the design of fuzzy self-tuning PID regulation system algorithm integrated by fuzzy control and conventional PID control is implemented. Marine diesel engine speed regulation by conventional PID and fuzzy self-tuning PID control algorithm have simulated in Matlab/Simulink environment.With the control effect of both control algorithms, results of the simulation are compared and analyzed.

The simulation results show that, for nonlinear and parameter time-varying characteristics of marine diesel engine speed regulation, the proposed governor achieves much better performance in dynamic and static stability, which effectively improves speed control of diesel engine performance compared with conventional PID method.

\section{References}

[1] G.C.Zhang, G.Ren.Transactions of CSICE. vol 27(2009)259-264.

[2] Q.W. Song, M Grigoriadis Karolos. In: Proceedings of the American Control Conference. Denver, Colorado June (2003) 779-784.

[3] M.L.Huang. Journal of Marine Science and Application. 6 (2007) 51-57.

[4] Y.Shi, Z.D.Qi, L.Y.Zhang, et al. Transactions of CSICE. 30(2012) 563-568.

[5] H.Y.Wang, W.Zhang, H.T.ZHOU, et al. Transactions of CSICE, 26(2008 ) 452-456.

[6] Y.N.Yuan, L.Zhu, K.Yang, et al. Chinese Internal Combustion Engine Engineering. 27 (2006) 23-28.

[7] M Jung, K Glover, U Christen. Control Engineering Practice, 13 (2005)15-25.

[8] J.F.Arnold, N.Langlois, H.Chafouk. European Journal of Operational Research 193 (2009) 282-288.

[9] J. X.Dong, G. H.Yang. Fuzzy Sets and Systems 160 (2009)482-499.

[10] J.Liu, W.Wang, F.Golnaraghi, Eric Kubica. Fuzzy Sets and Systems, 161(2010)2746-2759. 